\title{
RESENHA
}

\section{PROCESSO EDUCATIVO DEMOCRÁTICO: formação integral para a tomada de consciência e de decisão}

José Antônio Borges ${ }^{1}$

FREIRE, Paulo. [1965]. Educação como Prática da Liberdade. 43. ed. Rio de Janeiro/São Paulo: Paz e Terra, 2018. ISBN: 978-85-7753-165-3.

O livro "Educação como Prática da Liberdade", de Paulo Freire, foi originalmente escrito em 1965, contém 189 páginas, e em sua 43a edição foi publicado pela editora "Paz e Terra". Esta obra possui um texto de apresentação de autoria de Francisco C. Weffort, uma composição poética de Thiago de Mello, intróito de dedicatória, agradecimento, esclarecimento, quatro capítulos e apêndice.

Na primeira parte da obra, com o título "Educação e Política: reflexões sociológicas sobre uma pedagogia da liberdade", Francisco C. Weffort expõe reflexões sociológicas a respeito da "Pedagogia da Liberdade" de Paulo Freire. Inicialmente Weffort realça que referida pedagogia tem como primeira exigência a prioridade da prática, cujo ponto de partida e desenvolvimento estão atrelados à vivência de Paulo Freire e do povo brasileiro, especialmente nas décadas de 50 e 60. Weffort explica que, na pedagogia em questão, a liberdade tem posição de destaque, "[...] na medida da participação livre e crítica dos educandos" (FREIRE, [1965] 2018, p. 09), que são tratados como alfabetizandos e não analfabetos. Com efeito, a discussão deve guiar o aprendizado, no qual a palavra é vista como tema de significação (situação) real, unindo alfabetização e

\footnotetext{
1 Mestrando em Educação Profissional e Tecnológica (ProfEPT) no Instituto Federal de Educação, Ciência e Tecnologia do Triângulo Mineiro (IFTM) - Campus Avançado Uberaba Parque Tecnológico/Brasil. ORCID iD: https://orcid.org/0000-0001-7206-7026. E-mail: joseantonioborges@hotmail.com
} 
conscientização. Segundo Weffort, essa visão educacional tem em sua dimensão prática, política e social, o exame crítico das condições históricas vigentes, de tal sorte que a ideia de liberdade possui plena significação quando constitui expressão de luta do homem por libertar-se. Ele afirma que a experiência do movimento brasileiro de educação popular foi vitoriosa, tendo em vista que em poucos meses dezenas de milhares de trabalhadores foram alfabetizados e alguns milhares de jovens e estudantes foram preparados para as tarefas de coordenação, além desses estudos perdurarem até os dias atuais, 2018, e serem irradiados a outros países, em que pese o abalo provocado pela ascensão da ditadura militar ao poder. Esclarece Weffort que se a conscientização possibilita manifestar descontentamentos sociais é porque subsistem situações reais de dominação, fruto de circunstâncias históricas e que podem ser mudadas. Já Paulo Freire centra sua análise acerca deste processo de transformação na "crise de valores", os estados (mundo) da consciência, uma preocupação educativa. Os valores de uma sociedade-objeto ou fechada, povo separado da elite e restrição ao diálogo, de acordo com ele, entrou em crise, anunciando tendências à democracia, vista como possibilidade histórica que depende da opção concreta do homem, efetivada por meio da luta. Para as elites, consoante Weffort, o movimento de conscientização, que permite fazer cidadãos politicamente ativos ou politicamente disponíveis para a participação democrática (cada homem um voto), representava o fim da democracia. Daí a relevância política de exclusão dos analfabetos e de conter o movimento de educação popular. Por fim, Weffort aborda o perigo do populismo, que, a despeito de encerrar mobilização democrática, atua na condição de intermediário entre as elites e as classes populares, inclusive para manipular as massas.

$\mathrm{Na}$ segunda parte, denominada "Canção Para os Fonemas da Alegria", Thiago de Mello entoa em sua escrita canção que homenageia o educando em sua descoberta das palavras e do mundo que o cerca, desvelando a releitura da vida que a alfabetização crítica proporciona. 
No tópico inaugural nomeado "Esclarecimento", Paulo Freire assinala que seu esforço educativo foi influenciado pelas condições da sociedade brasileira à época, contraditória, de profundas desigualdades, comandada por uma "elite" e na qual o homem era tido mais como "coisa". Segundo ele, as respostas aos dilemas em tela passam pela opção da educação para o homem-sujeito, enquanto força de mudança e libertação, por meio de "autoreflexão e de reflexão sobre seu tempo e seu espaço" (FREIRE, [1965] 2018, p. 52). Tratar-se-ia da ampla conscientização das massas.

No capítulo 1, "A Sociedade Brasileira em Transição", Paulo Freire pontua que há uma multiplicidade de transcendência do homem com o mundo, visto que ele responde à ampla variedade dos desafios e também diferentemente a um mesmo, denotando pluralidade na sua singularidade e alterando-se no próprio ato de responder. O autor acrescenta que o conceito de relações humanas inclui criticidade, naturalmente existente, na medida em que a interligação dos dados captados é reflexiva. Nesse ato de reflexão, discernimento, está a raiz da "[...] descoberta de sua temporalidade, que ele começa a fazer precisamente quando, varando o tempo, de certa forma então unidimensional, atinge o ontem, reconhece o hoje e descobre o amanhã" (FREIRE, [1965] 2018, p. 57). Dessa forma, a noção de historicidade, que liberta o homem da unidimensionalidade, permite que ele deixe a posição de espectador e interfira sobre a realidade. Segundo o autor, a integração do homem ao seu contexto se aperfeiçoa com a consciência crítica. Em assim sendo, Paulo Freire conclui que os fatores que levam à acomodação constituem a grande luta do homem, sendo necessário que se aproprie dos temas e tarefas fundamentais para dinamizar o seu mundo, dominar a realidade e humanizá-la. De acordo com o autor é possível notar que, em qualquer seara, a cada dia o homem simples tem sido mais esmagado e diminuído, transformado em espectador, dominado pelo poder dos mitos e das forças sociais detentoras de poder. A educação, à época do Golpe de 64 (e nos dias atuais), aparece como tarefa de suma importante ao se contrapor à estrutura antidialogal, de população alienada. Paulo Freire ressalta que a sociedade brasileira, nas 
décadas de 50 e 60, havia entrado na época de trânsito, em que emerge para exigir a ingerência, a participação que implica na tomada de consciência. A solução aos problemas angustiantes do povo, na passagem da fase de transição, segundo o autor, está na humanização do homem brasileiro por meio da educação reflexiva. Logo, esta educação dialogal e ativa conduz à transitividade crítica e confere profundidade na interpretação dos problemas, assegurando retorno à matriz da democracia.

No capítulo 2, nominado "Sociedade Fechada e Inexperiência Democrática", Paulo Freire analisa as raízes da sociedade brasileira, é dizer, a "inexperiência democrática" nacional, barreira à democratização que pode ser superada. O autor aclara que as condições desfavoráveis às experiências de autogoverno têm início já na colonização, sobretudo porque foi uma empreitada de exploração comercial da terra, frise-se, predatória, com base de organização social escravista, conforme citação de Caio Prado (apud FREIRE, [1965] 2018, p. 91). Em virtude da tendência dos conquistadores de visarem só o lucro e de não se fixarem na terra, povoando-a, a posse do território se fez por meio de grandes fazendas, com extensão de léguas para confinar com vizinhos, circunstância que favoreceu a cultura de "proteção" àqueles que viviam na propriedade dos senhores todo-poderosos. Assim, continua Paulo Freire, floresce a dependência e o mandonismo, típicos da estrutura de grande domínio do paternalismo. Logo, houve carência de vivência comunitária, pois predominou a nãoparticipação do homem na busca da solução dos problemas comuns. A chegada da família real ao Rio de Janeiro, segundo ele, provocaria mudanças: de um lado a possibilidade de realizar experiências democráticas, com a criação de escolas, da imprensa e do ensino técnico, bem assim com a transferência de poder do patriciado rural para as cidades; de outro ratificava as tradições antidemocráticas, concentrando o poder na burguesia que enriquecera no comércio e também nos doutores formados na Europa, além da preservação do trabalho escravo. O autor anuncia que a desconsideração do abordado contexto ("clima" feudal e homem vencido e "mudo"), ou seja, a adoção de soluções rotuladas não 
permitiu a emersão do povo. Demais, Paulo Freire aponta que a sociedade brasileira entra na fase de transição, no século XIX, com as mudanças provocadas pelas restrições no tráfico de escravos, em seguida com a abolição da escravidão e a política de atração de imigrantes, primeira tentativa de "crescimento para dentro" na economia. Impulso maior sobreveio com o surto de industrialização, na década de 20 e 30, atrelado à crescente urbanização e a outras múltiplas mudanças, nas artes, literatura e ciências, a permitir o conhecimento e a identificação do homem com a realidade nacional. Desta feita, iniciou-se a experiência da participação.

No terceiro capítulo, designado "Educação versus Massificação", Paulo Freire manifesta que o educador brasileiro deve ter a preocupação de atuar com vistas à educação crítica e criticizadora. Educação esta que permita o constante diálogo com o outro, que acentue a consciência da revisão de prescrições alheias e a coragem de lutar. Ainda assim, o autor torna patente a necessidade de mudança de todo o processo educativo, "reforma que atingisse a própria organização e o próprio trabalho educacional em outras instituições" (FREIRE, [1965] 2018, p. 117). No enfoque de Paulo Freire, a educação deve estar voltada para o desenvolvimento e para a democracia, capazes de enfrentar os instrumentos de massificação, como a produção em série, do comportamento mecanizado pela reiteração de ato único, que impõe antolhos ao homem e o "domestica" pela ausência da atitude crítica e do estreitamento da especialização descomedida. E isso se dá com mudança de atitude, em que a educação constitui ação social que incentiva e implementa hábitos de participação e ingerência, superando não apenas o analfabetismo, mas também a inexperiência democrática, de posição ingênua e passiva. Nesta passagem - autor enfatiza a importância da educação integral, que nomeia humanista e tecnológica, em que a formação do trabalhador (técnico) avança além dos problemas de sua especialidade. Convém notabilizar que ele concebia a formação integral e integrada, no caso também projeto social contra-hegemônico dos trabalhadores, objeto de estudo e alvo, por exemplo, dos Institutos Federais de Ensino no século XXI, com sua 
verticalização (que permite continuidade dos estudos até lograr formação stricto sensu) e visão de mundo ampliada para superar as amarras da mera ocupação assalariada do mercado neoliberal.

No quarto e derradeiro capítulo, intitulado "Educação e Conscientização", Paulo Freire demonstra sua preocupação com os déficits educacionais, isto é, com os elevados números de crianças sem escola e igualmente de analfabetos, bem assim com a intransitividade de consciência das populações rurais. O autor procurou engendrar método que superasse tais problemas, com especial atenção para as bases populares. Por esse ângulo Paulo Freire buscou efetivar a própria Declaração Universal dos Direitos do Homem, que, por meio do ensino e da educação, deve assegurar o reconhecimento de que os homens nascem livres, são iguais em dignidade e direitos, dotados de razão e consciência, tendo direito ao pleno desenvolvimento de sua personalidade humana, à liberdade de pensamento, consciência, religião, opinião e expressão, além de tomar parte no governo. Em suas experiências sempre repeliu a adoção de fórmulas pré-concebidas, a serem impostas e destoantes da realidade. Ao invés disso, primou pela participação crítica dos educandos a resultar na construção conjunta, inclusive do método a ser considerado na visada experiência de democratização da cultura. Na última parte do capítulo em tela o autor narra a execução do método que criara e destaca a indispensabilidade da conscientização para que o adulto se alfabetize e possa se politizar, conformando o resguardo da destinação democrática.

O livro, autêntica proposta de alfabetização atrelada à emancipação (nos dizeres do autor emersão) democrática e ao despertar do homem enquanto sujeito, é aconselhado a todos que se interessem pela história, pela educação e pelos problemas que afligem a população brasileira.

Recebida em: 19 de outubro de 2018. Aprovada em: 13 de maio de 2019. 